\title{
A Structural Analysis of the First Cardington Test.
}

\author{
M. Gillie, A.S. Usmani ${ }^{\dagger}$ and J.M. Rotter \\ School of Civil and Environmental Engineering \\ University of Edinburgh \\ Edinburgh EH9 3JN, United Kingdom \\ $\dagger$ Corresponding author
}

\section{Abstract}

This paper presents a finite element analysis of the first Cardington test using shell elements to model the concrete floor slab. The behaviour of these elements is defined using FEAST, a program that allows the behaviour of the shell elements to be defined within the commercial finite element package ABAQUS, using stress-resultants. The model of the test is described and the assumptions that were made are noted and justified. The results of the analysis indicate that the response of the structure is overwhelmingly dominated by the effects of thermal expansion and that material degradation and gravity loading are of secondary importance. It is noted that as a consequence of the rectangular nature of the fire compartment, tensile membrane action occurs from the beginning of the test.

\section{Introduction}

The behaviour of composite structures in fire conditions, such as the office buildings found in many European cities, is extremely complex. In recent years it has been accepted that the traditional methods of fire safety engineering have been developed from an inadequate understanding of the behaviour of heated structures. This has led to the application of expensive fire protection that may have been unnecessary in many cases. To allow the behaviour of structures in fire conditions to be studied, a series of tests were performed on a full scale, eight storey, steel-framed building in 1995 at Cardington, UK. ${ }^{1-3}$ These experiments produced a huge amount of experimental data and it 
was intended that this data be used to develop a detailed understanding of the physical phenomena which dominate structural behaviour under fire loading. This paper is concerned with gaining some of this understanding. The Cardington tests, together with recent advances in computing power and modelling techniques, have allowed a new generation of numerical models of heated structures to be developed. Previous research into modelling isolated structural elements and simple frames has shown that it is difficult to obtain accurate models even with experimental data available for verification. Clearly, attempting to model 3-dimensional structures with no experimental data would not have produced reliable predictions. The availability of the Cardington experimental data prompted a number of groups to attempt to model the fire tests and to obtain an understanding of the structural behaviour based on the results of their models.

Workers at Sheffield University have produced numerical models of the fire tests ${ }^{4-7}$ conducted at Cardington using the $\mathrm{VULCAN}^{6}$ finite element program, previously known as INSTAF. ${ }^{5}$ Earlier versions lacked geometic nonlinearity in the shell elements, this has now been addressed. Analysts at Imperial College, London have used the $\mathrm{ADAPTIC}^{8}$ finite element package to model the Cardington tests. ADAPTIC only includes beam elements and so the analyses have been performed by descretizing the Cardington tests in the form of a grillage. The results were reported in 2000 by Elgazhouli. ${ }^{9}$ This model included non-linear material behaviour, non-linear geometry and a full range of thermal effects. Researchers at Corus (previously British Steel) have developed a number of numerical models to investigate aspects of the Cardington tests. ${ }^{10-12}$ Models of the floor slab using linear elastic shell elements with discrete hinges where yield lines were expected to develop were produced for the first, third and fourth tests. The orthotropic nature of the slab was modelled by including beam elements attached to the shell elements in one direction. Although including hinges along predetermined lines is clearly an a priori assumption, Corus's models were able to provide useful insights into which aspects of the Cardington frame were dominant in governing its behaviour. Earlier work by the research group at Edinburgh University used the commercial finite element package, ABAQUS, ${ }^{13}$ to model the Cardington tests. ${ }^{11,12,14-17}$ Beam elements with fully non-linear material behaviour were used to represent the steel frame and a grillage of beam elements using a stress-resultant approach were used 
to model the floorslab. This approach allowed the material behaviour and geometry of the grillage beams to be combined but had the disadvantage of not allowing any interaction between bending and axial forces to be modelled. The constitutive behaviour of the grillage beams was determined by a simple trilinear model.

This brief overview of previous work in the area shows that to date all numerical work on analysing the Cardington structure has been lacking in one or more areas. Work using shell elements to represent concrete floors has tended to either use very simple material behaviour and include various ad hoc assumptions, or has not included numerical representation of key phenomena such as geometric nonlinearity. Work that has not been deficient in these respects has resorted to using a grillage of beam elements to represent a continuous floor slab. While all these models have been useful in gaining new insights into the behaviour of structures in fire conditions, it is clearly necessary for a more rigorous numerical model to be developed before any firm conclusions can be drawn. The need for such a model is made more important by the move towards performance based fire safety design codes. In addition, most previous work has concentrated on modelling the tests and obtaining accurate matches with experimental data. This is clearly necessary but a clear understanding of the key structural phenomena is also required. Unless engineers have a good understanding of how heated structures behave, they will not be able to take full advantage of modern performance based design codes.

This paper presents an analysis of the first Cardington test using the FEAST program. FEAST is a user-defined subroutine that can be used with ABAQUS to specify the behaviour of shell elements using stress-resultants. The use of FEAST means that the analysis accounts for full material and geometric non-linearity as well as thermal expansion, thermal curvature and non-linear thermal gradients. To date no other analysis has included all these aspects while using shell elements to model the Cardington floor slab. Full details of FEAST have been given elsewhere. ${ }^{18,19}$ The combination of FEAST and ABAQUS has the added advantage of using the highly optimised and well verified ABAQUS numerics. As well as describing the numerical model that was used, the paper also presents information on the forces that developed in the structure and attempts to disentangle the complex structural response. 


\section{The Finite Element Mesh}

The layout of a typical floor of the Cardington frame showing the position of each of the tests is shown in Fig. 1. Test one consisted of heating an internal secondary beam and the associated area of floor slab above it; the columns at each end of the beam were protected. The figure shows that in the test there was a considerable area of cold structure separating the heated compartment from the edge of the building on all sides. This cold area remained very stiff in comparison to the heated compartment and so the compartment was well restrained laterally. As a result, it was not necessary to model the entire floor for a realistic finite element mesh to be developed because the lateral restraint could be accurately represented by rigid horizontal boundary conditions. The symmetrical nature of the test was exploited in the finite element mesh. This approach resulted in the area of slab modelled extending from the middle of the heated compartment to the column in the direction of the heated beam and to mid-span in each of the unheated bays adjacent to the heated compartment. This is shown in schematic form in Fig. 2 and the finite element mesh is shown in Fig. 3. Eight noded, reduced integration, 3-dimensional shell elements were used in a $30 \times 30$ regular grid. At each of the boundaries vertical displacement and rotation about an axis parallel to the line of the boundary were allowed while all other degrees of freedom were fixed. This arrangement produced a symmetry condition at all edges of the slab. FEAST was programmed to model the slab using the concrete behaviour specified in Eurocode $2 .{ }^{20}$ As indicated in Fig. 2 the floorslab was orthotropic due to ribs running perpendicular to the tested joist; FEAST was programmed to take account of this. The terms "parallel to the ribs" and "perpendicular to the ribs" will be used to refer to forces etc. in the two directions.

The beams and column were modelled as I-section, 2-noded linear beam elements. This meant that the local flange buckling that was seen to take place in the Cardington experiment would not be captured

in the model. However it was shown by $\mathrm{O}^{\prime} \mathrm{Connor}^{10}$ that this local behaviour did not effect the overall predictions of numerical models. By using beam elements rather than shell elements considerable computational time and resources were saved. As with the slab, where the beam elements coincided 
with the edge of the mesh, symmetry boundary conditions were used. The column was modelled from one floor below the floor on which the test took place to one floor above it, also with 2-noded linear beam elements. The bottom end of the column was fully fixed whilst at the top only vertical deflections were permitted. The behaviour of the steel in the beams and columns was that defined in Eurocode $3 .^{21}$

In the experiment the beam to beam and column to column connections were half-depth end plates. ${ }^{3}$ Such connections can be assumed to have little or no moment capacity so pinned connections were used in the finite element model to represent this condition. The slab was connected to the beams by shear studs that provided a very high degree of restraint and so rigid connections were specified numerically.

There were two kinds of load applied during the Cardington experiment; a static load and a thermal load. The total static load was $5.48 \mathrm{kN} / \mathrm{m}^{2}$ and this was straightforward to apply numerically. The thermal loading was less easy to define. The Cardington floor slab had ribs on its under-surface meaning that the temperature varied depending on the section being considered as shown in Fig. 4 . In the analysis the temperature-time curve for the slab was obtained from the temperature sensor placed $75 \mathrm{~mm}$ below the top surface of a rib. The joist temperature-time curve was obtained from a sensor located on the web. These temperature profiles are shown in Fig. 5. The loading was applied in two stages. First the static load was applied while the structure was unheated. The structure was then heated according to the temperature-time curves described above with the static load remaining unaltered.

\section{Analysis of the Structure}

It is clear from even a casual study of the analysis of the experimental load case that the behaviour of the Cardington frame during test 1 is extremely complex (Figs. 6 to 16). This section will analyse the behaviour of structure as it was heated and identify the key structural events. So that the order of these events is clear, the tested beam lower flange temperature will be used as a reference temperature. 


\section{General Points}

Before discussing the physical behaviour of the structure it is worth emphasising the relationships between thermal, mechanical and total strains. At ambient temperature total strains and mechanical strains are equal and so lead to both stresses and deflections. This is no longer the case in heated structures where strains are related according to the following equations:

$$
\begin{aligned}
\epsilon_{t} & =\epsilon_{m}+\epsilon_{T} \\
\epsilon_{T} & =\alpha \Delta T \\
\text { where: } \quad \epsilon_{t} & =\text { total strain } \\
\epsilon_{m} & =\text { mechanical strain } \\
\epsilon_{T} & =\text { thermal strain }
\end{aligned}
$$

It is still true that total strains lead to deflections but it is now mechanical strains that lead to stresses.

That this is the case can be most clearly seen by considering the simple example of a uniformly heated fixed ended beam. As the beam is heated the thermal strains are completely cancelled out by mechanical strains of equal magnitude but opposite sign. The total strain and the deflections remain zero whilst stresses are induced as a result of the mechanical strain. If the fixed ends were now replaced with rollers, the mechanical strains and hence the stresses would be zero. Meanwhile the total strains and deflections would increase. These ideas have important consequences when it comes to considering deflections in heated structures. It is no longer necessarily the case that large deflections imply large stresses, or that the structure is close to failure, as is the case with structures at ambient temperature.

Total curvatures, thermal curvatures and mechanical curvatures are linked in a similar manner to 
strains:

$$
\begin{aligned}
\phi_{t} & =\phi_{m}+\phi_{T} \\
\phi_{T} & =\alpha \Delta G \\
\text { where: } \quad \phi_{t} & =\text { total curvature } \\
\phi_{m} & =\text { mechanical curvature } \\
\phi_{T} & =\text { thermal curvature } \\
G & =\text { thermal gradient (assumed linear) }
\end{aligned}
$$

The set of curves that are presented in this paper are complex and in many cases not smooth. When trying to determine the structural behaviour it is important to be aware that the nature of the curves can be determined by the form of the temperature loading as well as by structural effects. This can be seen, for example, by examining Fig. 12 which shows the variation of the force in the tested beam for the load case analysed, and Fig. 13 which shows the same quantity but with a linear increase in temperature for both the slab and and the beam. Most obviously the sharp jump that occurs in the force at $820^{\circ} \mathrm{C}$ with non-linear heating is absent with linear heating. The curves with linear heating are also noticeably smoother in other areas as well. Effects such as this occur in many of the curves that are presented.

\section{Deflections}

The steel joist had a low thermal capacity and high thermal conductivity and so its temperature remained close to the atmosphere temperature throughout the test. By contrast the concrete slab had a high thermal inertia and so it was only later in the test that its mean temperature started to rise significantly (Fig. 5). A consequence of this slow rise in the slab temperature was that the deflection behaviour in the early part of the test was controlled by the beam. As the beam temperature rose its thermal expansion was restrained directly by the cooler slab. The resultant thrust was eccentric 
to the composite slab-beam section and so forced the section into sagging curvature, thus producing deflections. This behaviour was dominant until about $120 \mathrm{C}$

At around $120^{\circ} \mathrm{C}$ the tested beam yielded in compression (see below and Fig. 12) so expansion no longer resulted in increasing axial force and the beam ceased to drive deflections. As the beam temperature continued to increase beyond $120^{\circ} \mathrm{C}$ the axial force decreased (Fig. 12) as a result of the declining material properties of the steel. If the sole cause of deflections beyond $120^{\circ} \mathrm{C}$ had been the thermal expansion of the steel beam, then the deflections would have stopped or even started decreasing as soon as the beam axial force began to reduce because the eccentric thrust would no longer have been sufficient to maintain the deformed shape.

There were a number of mechanisms that drove deflections after the tested joist yielded, all of which depended on rises in the slab temperature. At the time of the joist yielding the lower surface of the slab was starting to heat significantly while the upper surface remained cool, as can be seen in Fig. 4. This resulted in thermal gradients and hence thermally induced curvatures, both parallel and perpendicular to the ribs, which gave rise to increasing deflections. At higher temperatures still the thermal expansion of the slab parallel to the tested joist was sufficient to drive the deflections. This mechanism was resisted somewhat by tensile forces that developed in the ribs (Figs. 8 and 9). At the same time the temperature of the lower surface of the slab was becoming hot enough for degradation of material properties to reduce the slab's moment capacity, thus reducing its resistance to increasing deflections.

The changing importance of the different effects driving the deflections can be seen in Fig. 7. The figure shows the predicted deflections when the steel coefficient of thermal expansion is assumed to be zero and also when the concrete coefficient of thermal expansion (and therefore thermal gradient) are assumed to be zero. When the concrete thermal expansion is taken as zero, the predicted deflections approximate the test deflections quite well up to $200^{\circ} \mathrm{C}$ at which point the steel joist has yielded; beyond this the deflections are almost constant and have no relation to the test deflections. This behaviour is in line with the explanation given above. When the steel thermal expansion is assumed 
to be zero there is almost no predicted deflection before around $500 \mathrm{C}$, at which point deflections grow very rapidly. The behaviour can be likened to the Euler buckling of columns, although in this case there is no instability because the ends of the compressive member are fixed and so the deflected shape is effectively defined. Above around $800^{\circ} \mathrm{C}$ the behaviour of the model with no steel thermal expansion approximates the test behaviour fairly well. At such temperatures the steel has lost almost all its strength so the effects of the steel thermal expansion are almost negligible.

\section{Behaviour of Ribs}

The behaviour of the ribs (i.e. the slab perpendicular to the tested beam) is shown in Figs. 8 to 11. These figures show forces per unit width plotted against distance from the edge of the numerical model. The symmetry in the model is exploited so on the $x$-axes the unheated secondary beam is at $1500 \mathrm{~mm}$, the edge of the heated compartment at $3000 \mathrm{~mm}$ and the tested joist at $4500 \mathrm{~mm}$.

At mid-span (Fig. 8) the force in the ribs was tensile throughout the test and increased with increasing temperature. This tensile force is explained by compatibility. Since the length of the heated compartment was greater than its width, the increase in length in the ribs' direction due to thermal expansion was less than that in the direction of the heated joist. As a result tensile forces were produced in the ribs in areas of high deflection. The rib force at $850^{\circ} \mathrm{C}$ at mid-span was approaching the ultimate capacity of the ribs. As positions progressively nearer to the column are considered (Figs. 9 and 10) the tensile forces in the ribs can be seen to decrease until at one-eighth span the ribs were subject to increasing compression as the temperature increased. This is because nearer the column deflections were less than at mid-span but the amount of thermal expansion in the ribs was the same. The increase in length of the ribs due to changes in geometry was now less than the increase due to thermal strains and so compressive forces resulted.

Figure 10 shows the bending moments in the ribs at mid-span at various times during the test. The negative moments over the tested secondary beam were slightly larger as it was stiffer due to being connected directly to the column. In effect, the ribs were acting as a continuous beam over three 
supports. As the test progressed the hogging moments over the unheated beams increased as load was shed from the heated region. Within the heated region increasing hogging moments were produced by the developing thermal gradient within the slab, these moments, as noted above, helped produce deflections.

\section{Behaviour of the Tested Joist}

The force in the tested beam is plotted against temperature at various sections in Fig. 12. Until $120^{\circ} \mathrm{C}$ the force increased linearly with temperature indicating that the beam was subject to restrained thermal expansion while remaining in its elastic range. The gradient of the plot in this region for all the heated parts of the beam is about (-)11800N/C. For fully restrained expansion the expected value of this gradient can be obtained from the standard relationship:

$$
\begin{aligned}
\delta & =P L / E A \\
\text { where in this case: } \quad \delta & =\alpha L=1.3 \times 10^{-5} \times 9000=0.117 \mathrm{~mm} \\
E & =210000 \mathrm{~N} / \mathrm{mm}^{2} \\
A & =5160 \mathrm{~mm}^{2} \\
L & =9000 \mathrm{~mm}
\end{aligned}
$$

This gives a value of $14087 N / C$ for $P$. The discrepancy between the two figures can be explained by remembering that the beam in the numerical model was not fully restrained but deflected downwards. This resulted in a geometric lengthening of the beam and so a reduced increase in force per unit temperature rise. The thermal expansion forces produced in the tested beam by even fairly modest increases in temperature were sufficient to swamp the forces in the beam resulting from the composite action of the slab-beam section. This can be seen by comparing the curves at $0 \mathrm{C}$ and $200^{\circ} \mathrm{C}$ in Fig. 12 .

The figure shows that there was a fundamental change in the pattern of axial force in the beam during the first $200^{\circ} \mathrm{C}$ degrees of heating, which resulted from restrained thermal expansion. Beyond this 
initial phase the changes in axial force resulted from declining material properties and were smoother and more gradual. Figure 12 demonstrates that a fairly small temperature rise can lead to dramatic changes in structural behaviour.

From $120^{\circ} \mathrm{C}$ onwards the deformations of the joist were entirely plastic and so could not be recovered when the temperature dropped. Although the cooling phase of the test was not modelled numerically, the large plastic deformations of the beam explain the failure of the connections between the beam and columns that occurred during cooling in the test. On cooling the plastified beam would have attempted to contract and thus produced huge tensile forces over its entire length and through the connections.

When examining Fig. 12 it is noticeable that the curve showing the variation of axial force for the section of the beam at 0.02 span has a slightly different form to the other curves. Up to the point at which the beam yields it can be seen that the curves for all the other sections of the beam are parallel while this section has a slightly smaller slope. Beyond this point the curve shows this section of the beam carries more axial force than the other sections. These differences arise in part because the heated compartment finished just short of the column and so the part of the beam at 0.02 span remained unheated during the test. In addition, the proximity of the primary beam meant that forces could be carried through the slab from the tested beam to the primary beam.

\section{Behaviour of the Heated Composite Section}

To understand the behaviour of a composite structure it is useful to think in terms of the behaviour of composite members. In test 1 the behaviour of the heated joist and associated area of slab is clearly crucial to understanding the structural behaviour. Since the concrete slab was continuous between secondary beams a suitable width of slab that was deemed to act with the steel joist had to

be determined. In this analysis an effective width of $2250 \mathrm{~mm}$ was chosen, in line with the Eurocode design recommendations.

The force in the width of slab acting compositely, the force in the composite section and the moment 
over the section are shown in Figs. 14 to 16 . The composite moments were calculated about an axis mid-way between the geometric centroid of the steel section and a point $70 \mathrm{~mm}$ up from the lower surface of the ribs. All these graphs show abrupt changes in value near the column. These abrupt changes resulted from numerically predicted hot spots that occurred in the slab near areas that were unheated and highly restrained. The hot spots are likely to be more marked in the numerical model than in reality and it is suggested that the values very near the column are treated with a degree of scepticism.

The force in the slab increased until about $400^{\circ} \mathrm{C}$ before decreasing as the slab material properties declined (Fig. 14). At ambient temperature the pattern of forces was determined by the deflected shape of the slab with tensile forces occurring near the column and compressive forces at mid-span. In a similar way to the tested beam, this pattern changed soon after the heating began. $\mathrm{By} 200^{\circ} \mathrm{C}$ the forces in the slab were almost uniform along the entire heated length and were produced almost entirely by restrained thermal expansion. At higher temperatures the force at mid-span was slightly less than near the column. The pattern of the composite axial forces (Fig. 15) followed similar trends to the slab forces but, because the joist was heated more quickly than the slab, two peaks occurred. One occurred when the joist force peaked at around $120^{\circ} \mathrm{C}$ and the second when the slab force peaked between $400^{\circ} \mathrm{C}$ and $600^{\circ} \mathrm{C}$.

The moments in the composite section are shown in Fig. 16. As expected, at ambient temperature the moments were governed by the curvature of the composite section; hogging was present near the column and sagging at mid-span. The axial forces in both joist and section of slab acting compositely have been shown to quickly become dominated restrained thermal expansion. Since the composite moments were determined by these forces, they too resulted from thermal expansion at even quite modest temperatures. By $200^{\circ} \mathrm{C}$ the composite moment for all three effective widths had changed from the ambient temperature distribution and had become almost uniform along the full length of the beam. The joist yielded by $200^{\circ} \mathrm{C}$ so from this point onwards the changes in composite moments are largely governed by changes in the force in the slab section; it can be seen that the changing composite moment follows a similar trend to the changing slab force (this ignores the declining force 
in the joist due to material degradation).

\section{Discussion}

At ambient temperature the only loads on the structure were gravity loads. The way these were carried is well understood by structural engineers and it is tempting to assume the response of the structure continues to be dominated by gravity loads at high temperatures. However, it is clear from the figures that this is not the case. The forces and deflections in the structure developed largely as a result of restrained thermal expansion and were relatively independent of gravity loading. This point is shown clearly in Fig. 17 which shows the test deflections, the numerically predicted deflections and the predicted deflections with the gravity loading tripled. The difference in predicted deflections is almost uniform throughout the test showing that it is only at ambient temperature that the magnitude of gravity loading is important.

Test 1 was an extremely restrained test in a highly redundant building. This meant the effect of declining material properties on deflections was complex. The degree to which the structure deflected has been shown to be largely dominated by restrained thermal expansion. Any thermal expansion not absorbed by elastic or plastic mechanical straining had to produce deflections. A consequence of this observation is that a reduction in material properties could actually reduce deflections by allowing a greater proportion of the thermal expansion to be absorbed by mechanical straining. This effect was strongly apparent in Fig. 7 - when the concrete coefficient of thermal expansion was taken as zero, the declining strength of the steel meant that the deflections stopped increasing. The traditional assumptions about declining material properties are very much at odds with this argument. It is normally thought that a reduction in strength leads to increasing deflections until the structure no longer has the means to withstand the applied loads, and collapses. In very simple determinate structures this is clearly the case and will also be the case in redundant structures once all alternative load carrying mechanisms have been used. The results from this analysis indicate however that the structure was some way from collapse and that the declining material properties were not responsible 
for significant increases in deflection.

At high temperatures the load carrying capacity of the heated steel joist had been almost entirely lost and the load carrying capacity of the slab parallel to the joist was very low. This resulted in the most significant load carrying mechanism being tensile membrane action in the ribs, as was shown to occur in Figs. 8 and 9. The failure criteria of heated structures is subject to some debate but from a structural point of view it is clear the collapse of an area of floorslab is unacceptable. The tensile capacity of concrete can be neglected so an idea of the how close the structure came to failure can be obtained by examining the mechanical reinforcement strains in the ribs at the end of test. These are shown in Fig. 18. The figure gives a plan view of the area of slab that was modelled with the locations of the beams marked. The values of reinforcement strains are given although these should be taken as indicative only because effects such as strain concentrations at cracks in the concrete were not modelled. It can be seen that the values are relatively low, even at midspan, indicating that the floor was not about to fail.

The first Cardington test consisted of a small and somewhat artificial compartment. Many real structures, such as office buildings, are fairly open plan and a typical fire compartment would be much larger than that in the test. The shape of the compartment was also unusual in that it was

significantly longer than it was wide. These points mean that care must be exercised in extraplotaing the results to predict the effects of larger fires. In particular the degree of restraint to thermal expansion may well be less in a larger compartment. The analysis of the third Cardington test, which was much larger, will be the subject of the next Chapter.

\section{Conclusions}

It is concluded from this investigation in this Chapter that for well restrained compartment fires in highly redundant buildings:

- The effects of the thermal expansion are dominant in producing deflections and forces. 
- Material degradation and gravity loading have only a minor effect of deflections and forces. 


\section{References}

[1] P.N.R. Bravery. Cardington Large Building Test Facility. Technical report, iki, c1993.

[2] D.M. Martin, B.R. Kirby, and M.A. O'Connor. Behaviour of a Multistorey, Steel Framed Building Subjected to Natural Fire Effects, Final Report. Technical report, British Steel, 1998. Confidential report.

[3] B.R. Kirby. The Behaviour of a Multi-storey Steel Framed Building Subjected to Fire Attack, Experimental Data. Technical report, British Steel, 1998.

[4] C.G. Bailey, I.W. Burgess, and R.J. Plank. Computer Simulation of a Full-scale Structural Fire Test. The Structural Engineer, 74(6):93-100, March 1996.

[5] P.S. Rose, I.W. Burgess, R.J. Plank, and C.G. Bailey. The Influence of Floor Slabs on the Structural Behaviour of Composite Frames. In Lee, editor, Structures in the New Millennium, 1997.

[6] Z. Huang, I.W. Burgess, and R.J. Plank. Nonlinear Analysis of Reinforced Concrete Slabs Subjected to Fire. ACI Structural Journal, 96:127-135, Jan-Feb 1999.

[7] Z. Huang, I.W. Burgess, and R.J. Plank. Three-dimensional Modelling of Two Full-scale Fire Test on a Composite Building. Proceedings of the Institute of Civil Engineers, Structures and Buildings, 134(1):243-255, 1999.

[8] B.A. Izzuddin and A.S. Elnashai. ADAPTIC: A Program for Adaptive Dynamic Analysis of Space Frames, User Manual. Imperial College, London, 1989.

[9] A. Y. Elgazhouli, B.A. Izzuddin, and A.J. Richardson. Numerical Modelling of the Structural Fire Response of a Steel-Framed Building, CESLIC Report CC15, PIT Project Report MD15/AM7. Technical report, Imperial College, London University, 2000. Available at www.civ.ed.ac.uk/research/fire/projects/reports.html. 
[10] M. O'Connor. PIT Project Research Report MD7: BS/Test2 ABAQUS model using shell elements for the beam and beam general section for the slab. Technical report, British Steel, 2000. Available at www.civ.ed.ac.uk/research/fire/projects/reports.html.

[11] A.M. Sanad. BS/Test3 reference ABAQUS model using beam general section. Technical report, University of Edinburgh, 2000. Available at www.civ.ed.ac.uk/research/fire/projects/reports.html.

[12] A.M. Sanad, J.M. Rotter, and M.A. O'Connor. Finite Element Modelling of Fire Tests on the Cardington Composite Building. In Proceedings Interflam'99, volume 2, 1999.

[13] Hibbet, Karlson and Sorenson, Providence, Rhode Island, USA. ABAQUS Users' Manual, Vols I to III, Ver 5.8, 1998.

[14] J.M. Rotter, A.M. Sanad, A.S. Usmani, and M. Gillie. Structural Performance of Redundant Structures under Local Fires. In Proceedings of Interflam '99, volume 2, Scotland, 1999.

[15] A.M. Sanad. BS/Test1 reference ABAQUS model using beam general section. Technical report, University of Edinburgh, 2000. Available at www.civ.ed.ac.uk/research/fire/projects/reports.html.

[16] A.M. Sanad. PIT Project Research Report AM1: Analysis of Results from BS/TEST1 Models, Part A Grillage Models. Technical report, University of Edinburgh, 2000. Available at www.civ.ed.ac.uk/research/fire/projects/reports.html.

[17] A.M. Sanad. PIT Project Research Report AM6: Analysis of Results from BS/TEST3 Models, Part A Grillage Models. Technical report, University of Edinburgh, 2000. Available at www.civ.ed.ac.uk/research/fire/projects/reports.html.

[18] M. Gillie. Modelling Heated Composite Floorslabs with ABAQUS using a UGENS subroutine. In ABAQUS Users' Conference 2000. Hibbett, Karlsson and Sorenson, INC, 2000.

[19] M. Gillie, A.S. Usmani, and J.M. Rotter. Modelling of Heated Composite Floor Slabs with Reference to the Cardington Experiments. Fire Safety Journal, 2001. accepted for publication. 
[20] ENV. Eurocode 2, Design of Concrete Structures, 1992.

[21] ENV. Eurocode 3, Design of Composite Steel and Concrete Structures, 1994. 


\section{Captions to Figures}

Fig. 1 Layout of a typical floor of the Cardington frame showing the locations of the various tests. It should be noted that the tests were carried out on different floors.

Fig. 2 Schematic plan view of the area of the Cardington frame modelled for the analysis of test 1 .

Fig. 3 Plan view of the mesh used for the analysis of test 1.

Fig. 4 Variation of the slab temperature with time at various locations through its depth at a typical location.

Fig. 5 Slab and beam temperature-time curves used during the analysis of test 1 .

Fig. 6 Comparison of deflections at midspan.

Fig. 7 Comparison of the predicted deflections when the thermal expansion of the steel and concrete are assumed to be zero.

Fig. 8 Force per unit width parallel to the ribs at mid-span.

Fig. 9 Force per unit width parallel to the ribs at one-quarter span.

Fig. 10 Force per unit width parallel to the ribs at one-eigth span.

Fig. 11 Moment per unit width parallel to the ribs at mid-span.

Fig. 12 Axial force against temperature at various sections in the tested joist.

Fig. 13 Axial force against temperature at various sections in the tested joist assuming a linear increase in temperature.

Fig. 14 Slab force acting compositely at various temperatures assuming an effective width of $2250 \mathrm{~mm}$.

Fig. 15 Composite force at various temperatures assuming an effective width of $2250 \mathrm{~mm}$.

Fig. 16 Composite moment at various temperatures assuming an effective width of $2250 \mathrm{~mm}$.

Fig. 17 The effect of tripling the gravity load on deflections.

Fig. 18 Mehanical strains in the reinforcment parallel to the ribs at the end of the test. 


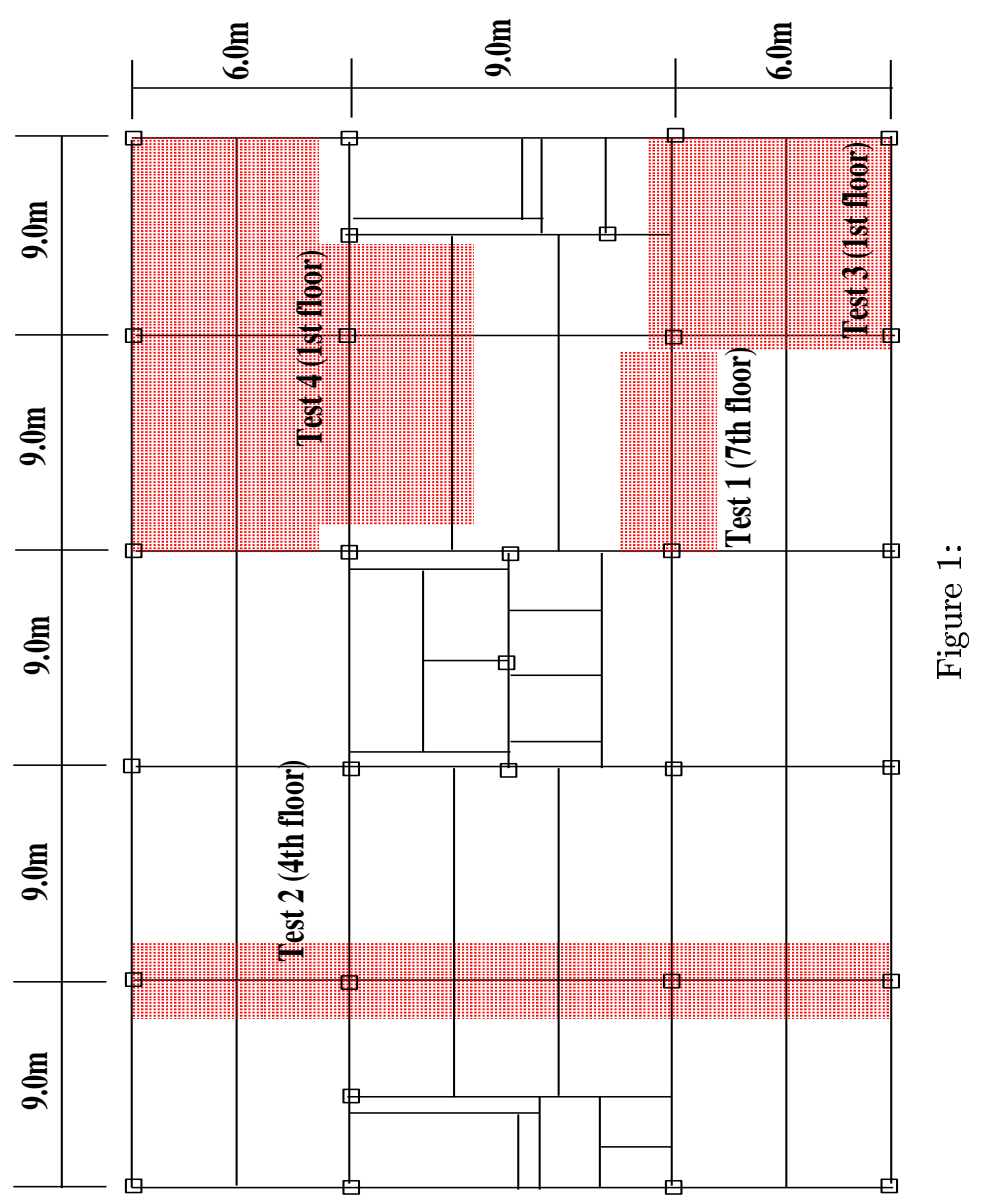




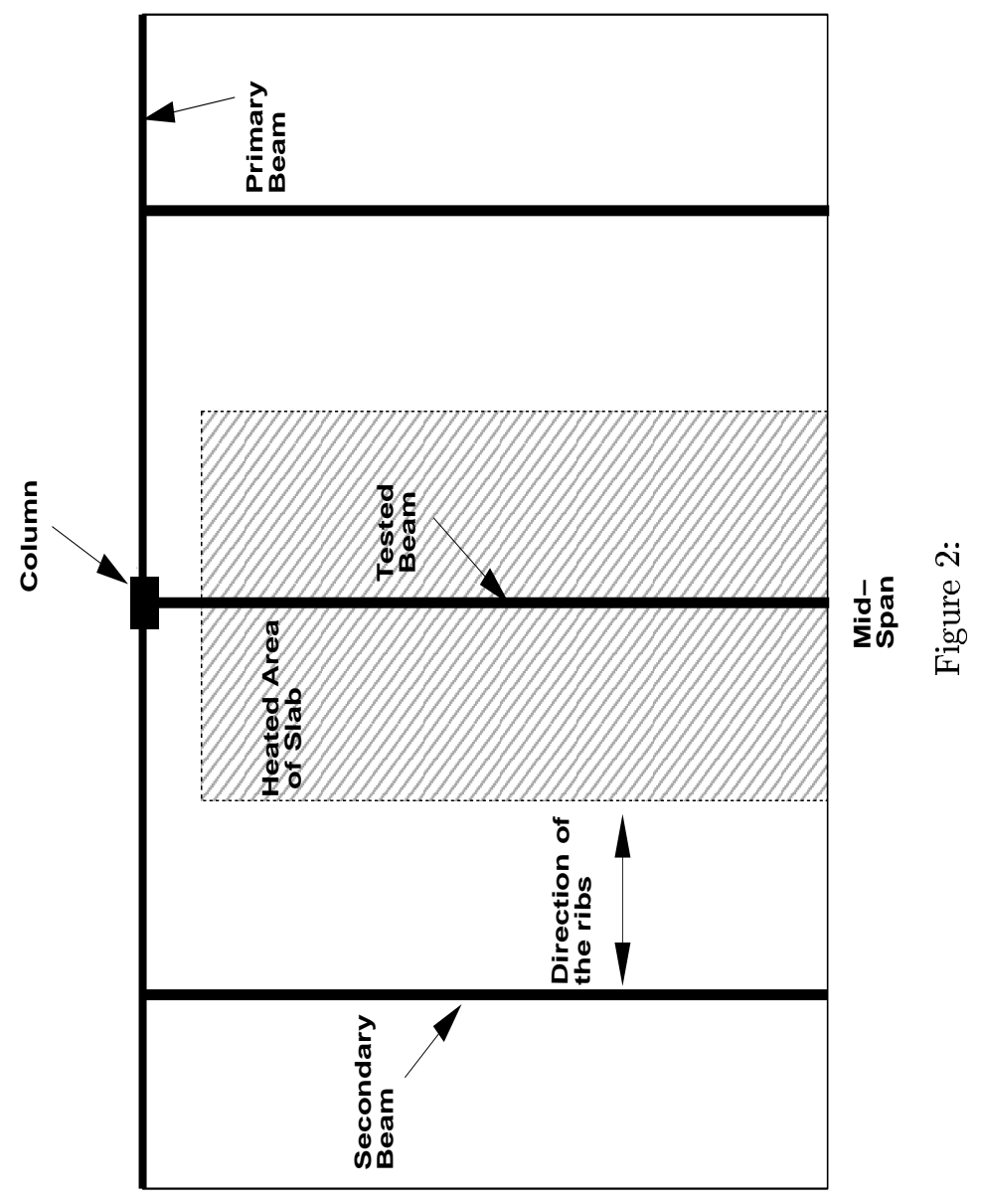



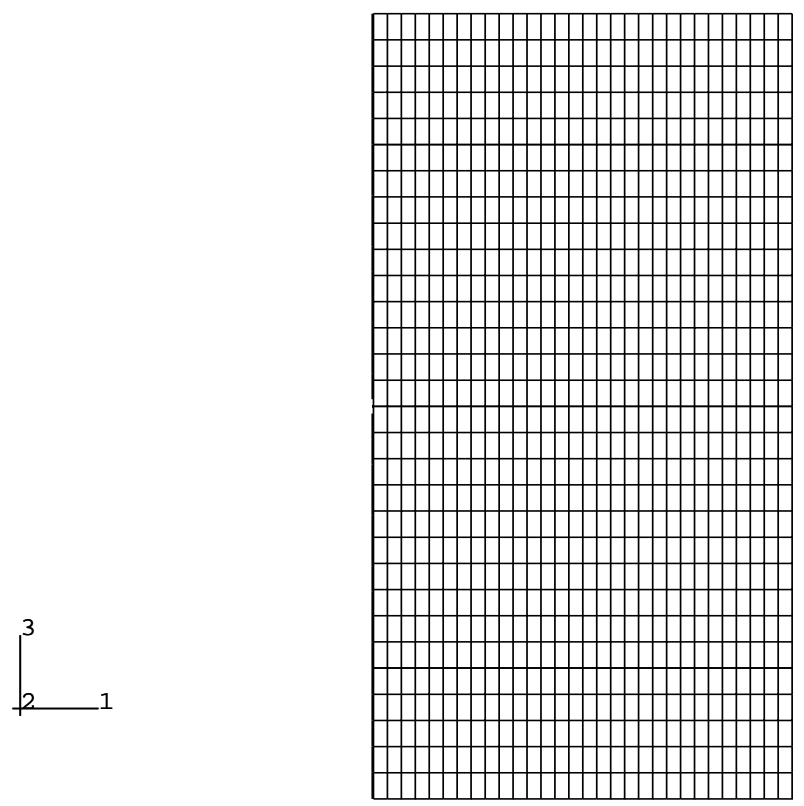

Figure 3: 


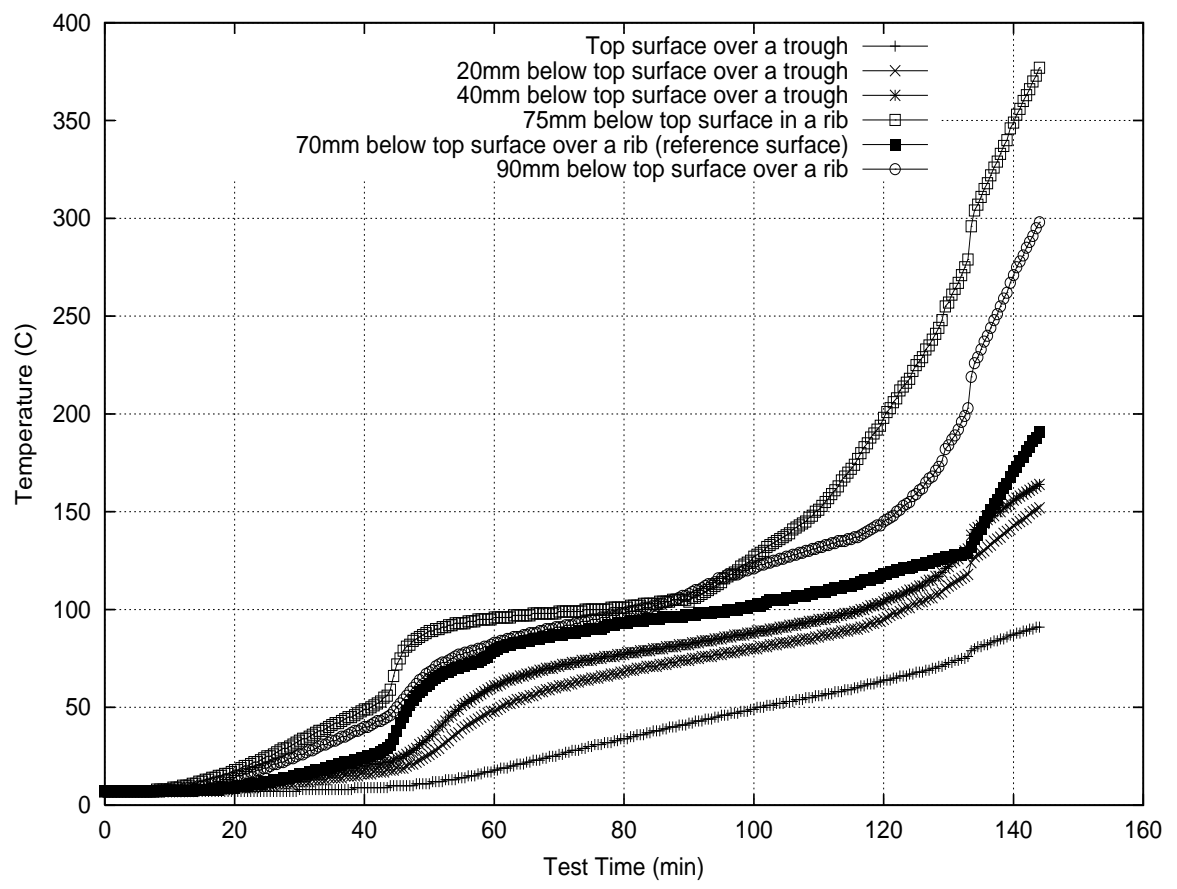

Figure 4: 


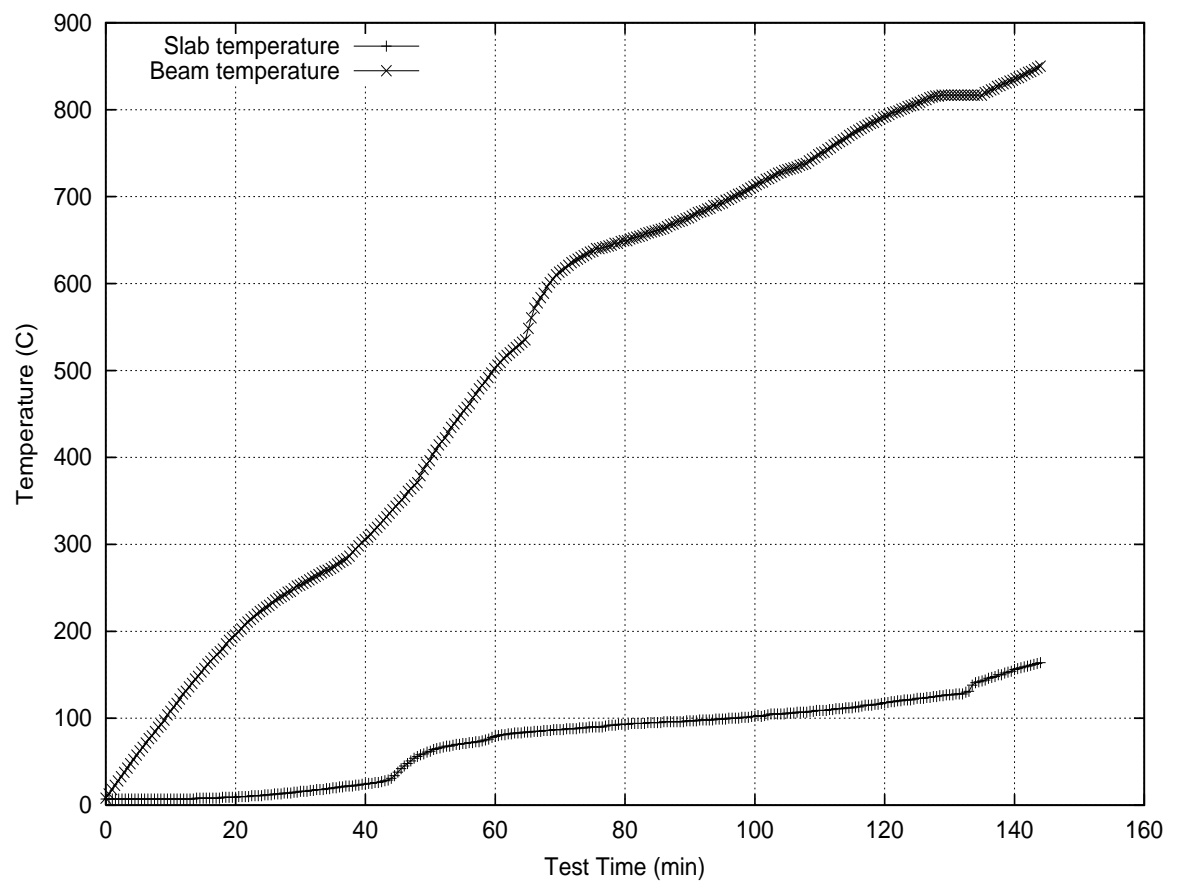

Figure 5: 


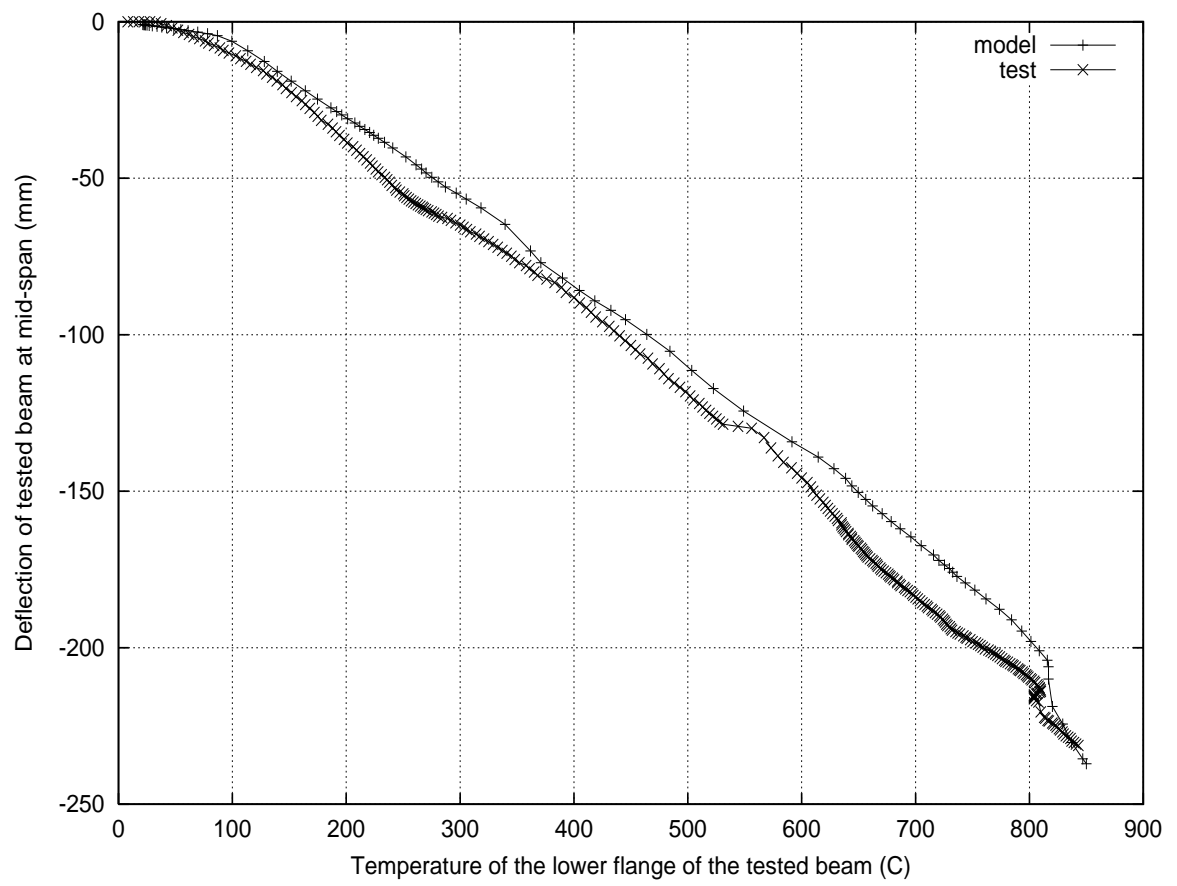

Figure 6: 


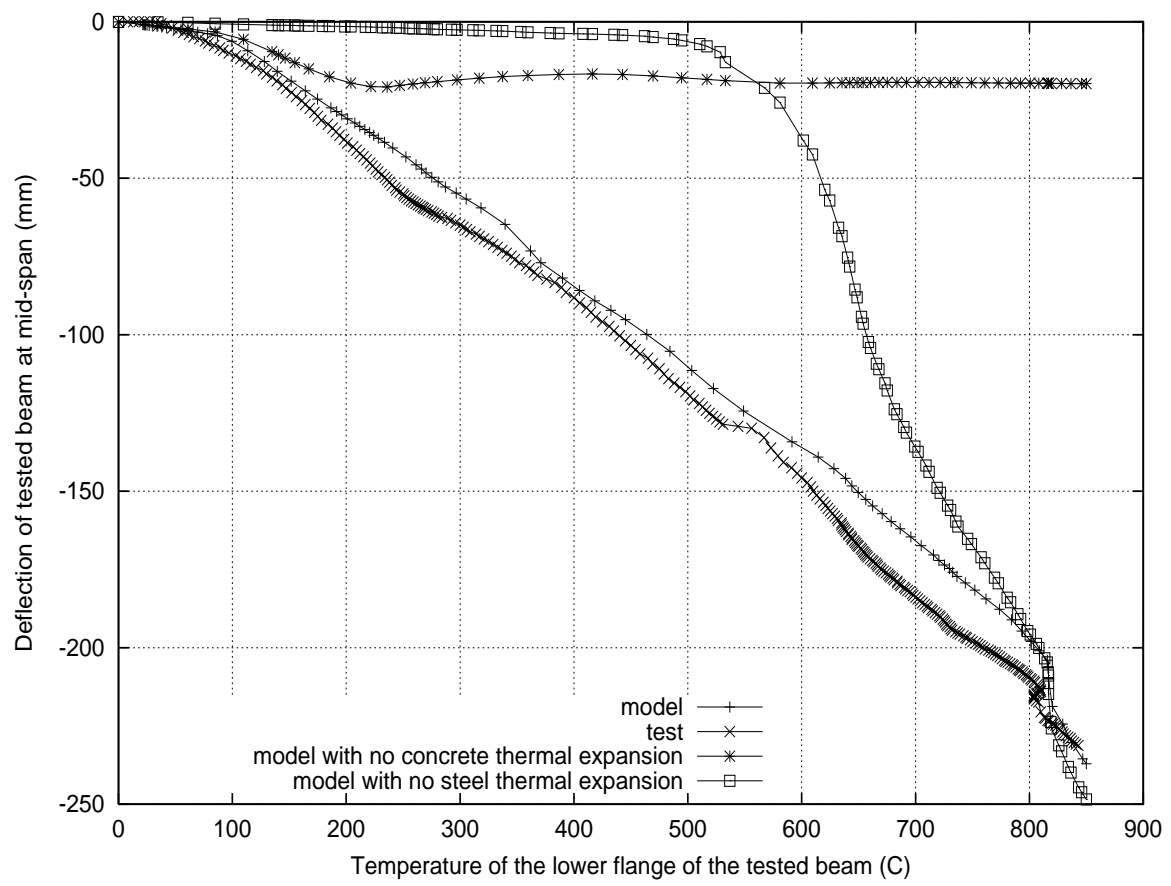

Figure 7: 


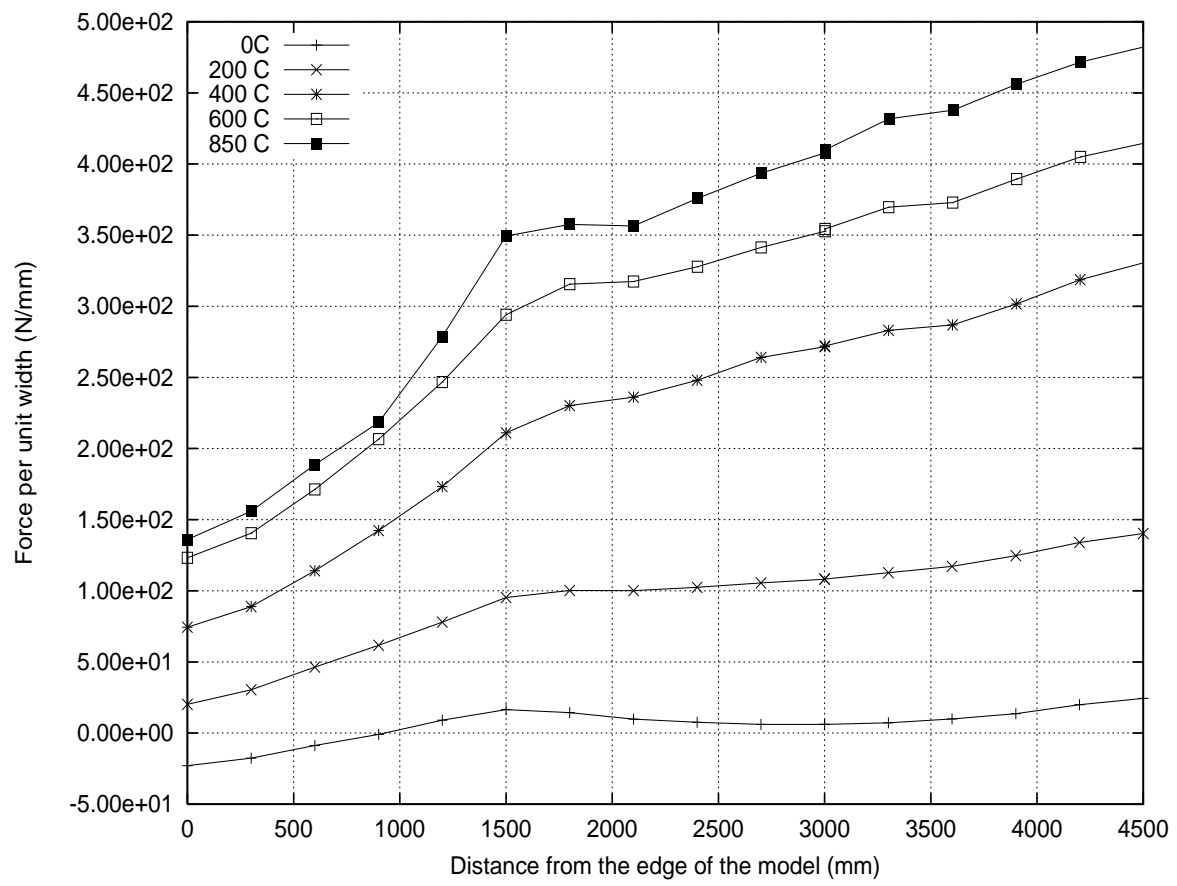

Figure 8: 


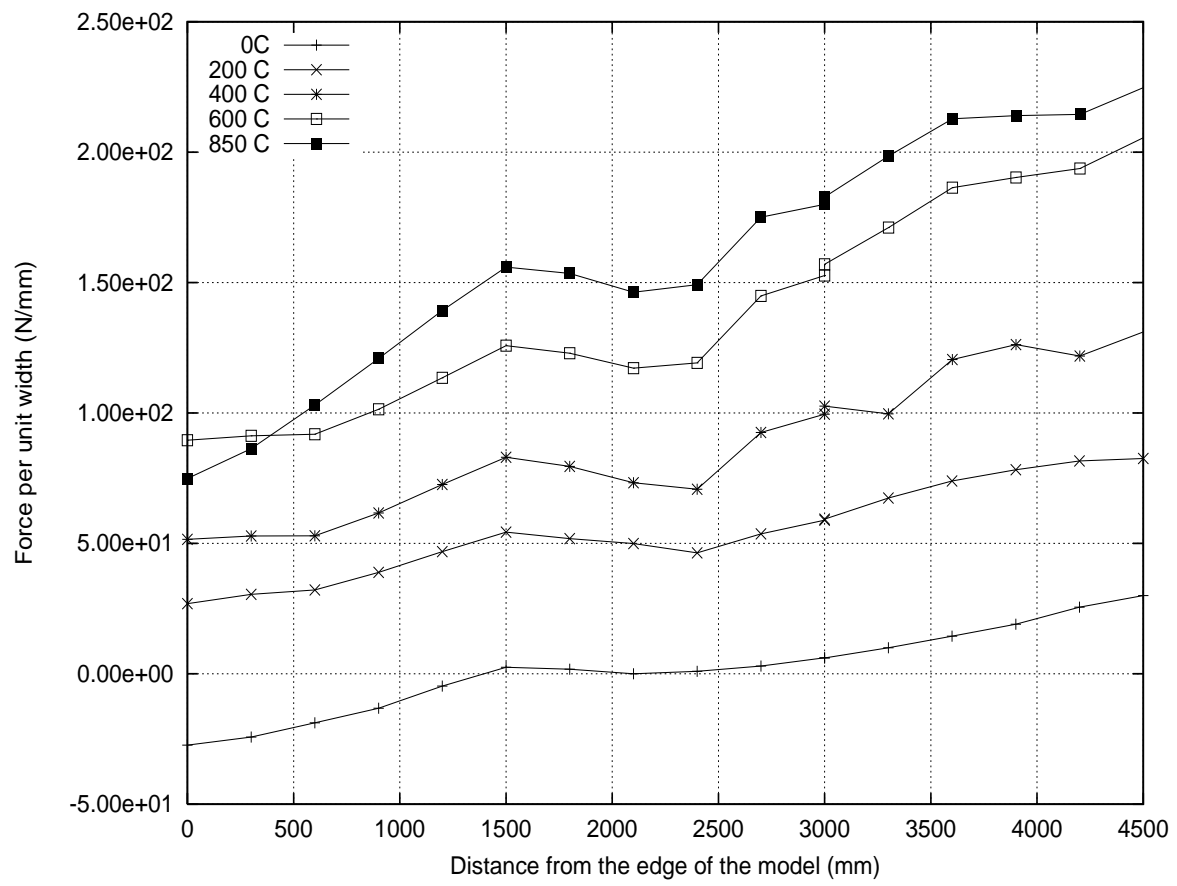

Figure 9: 


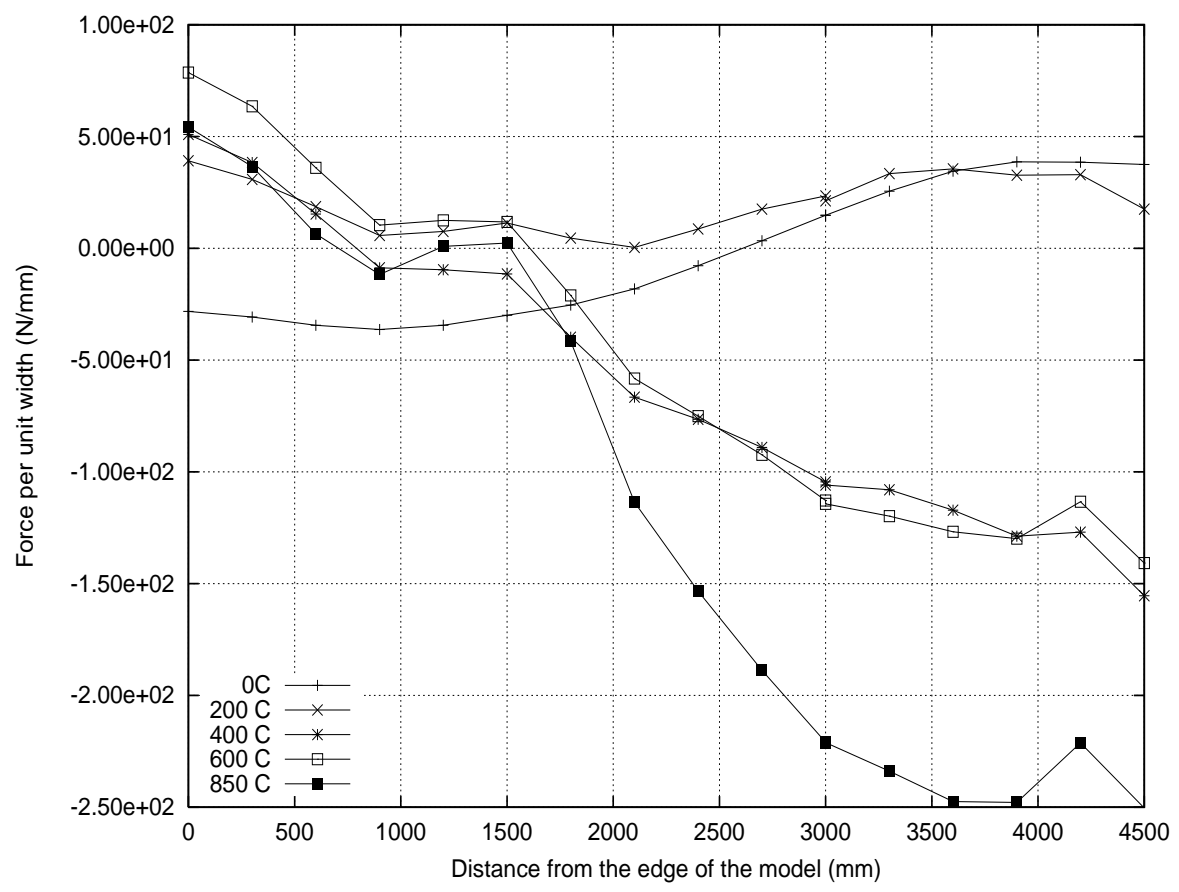

Figure 10: 


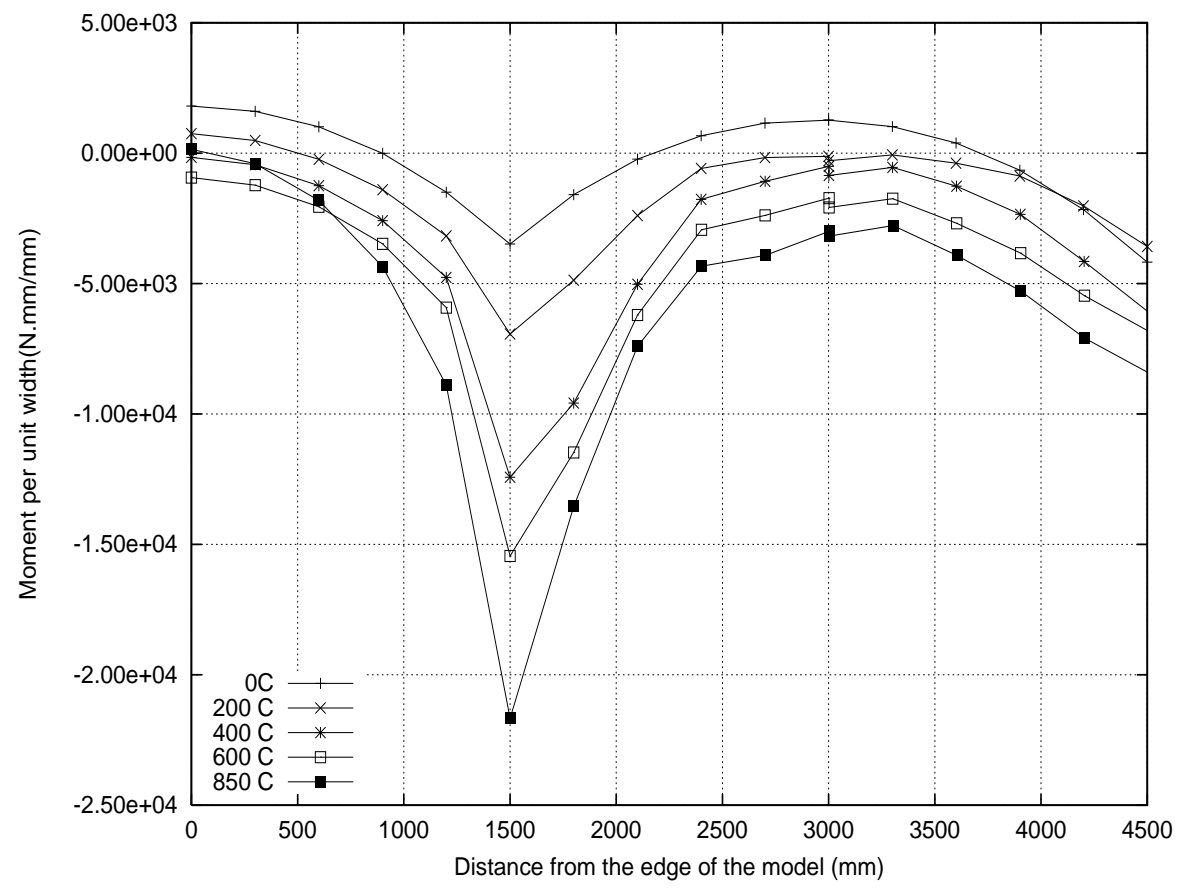

Figure 11: 


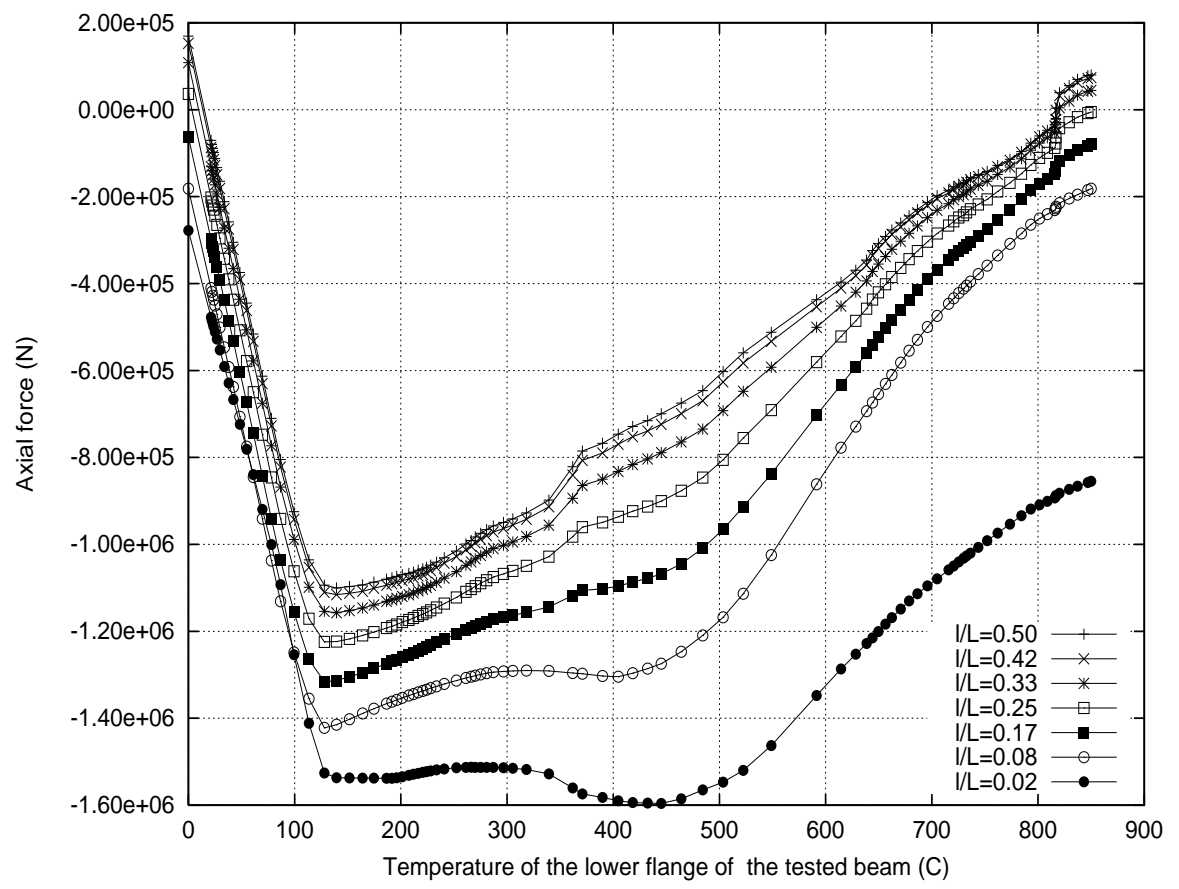

Figure 12: 


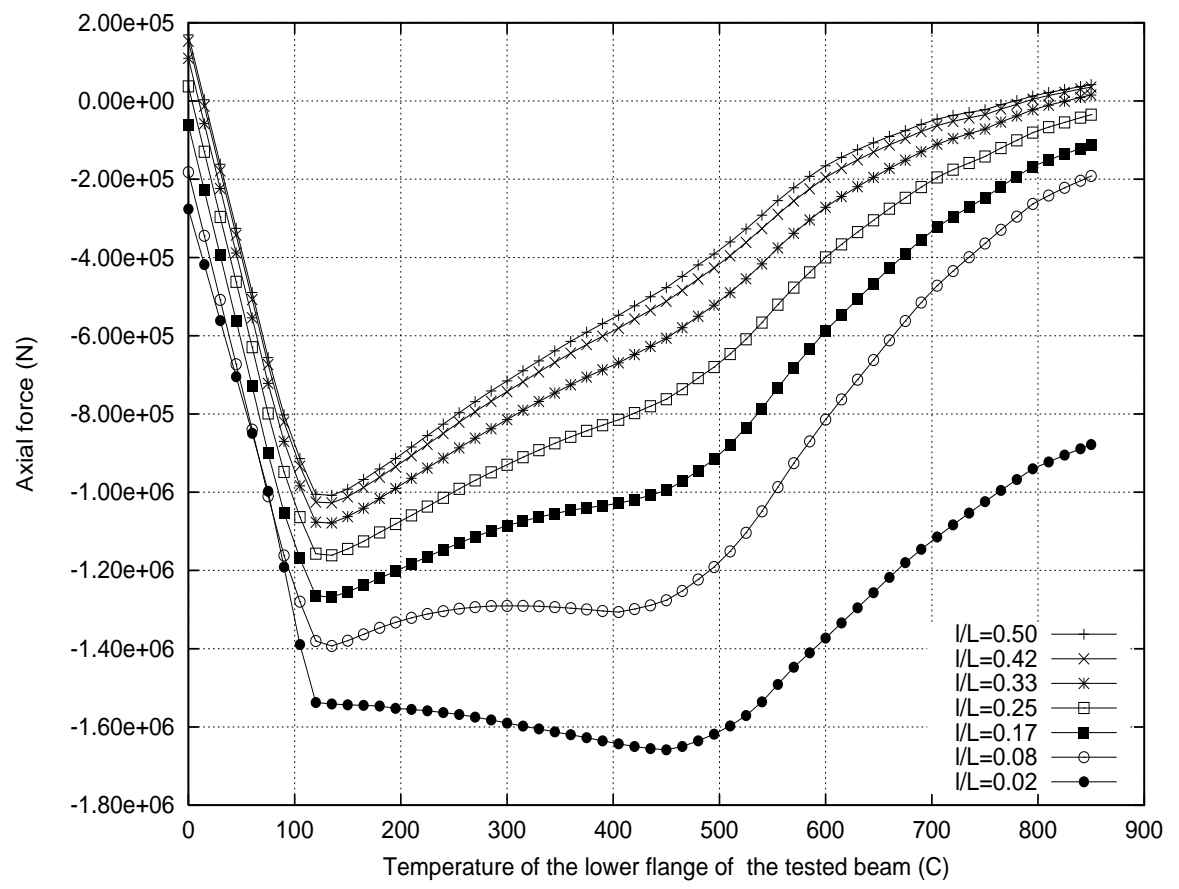

Figure 13: 


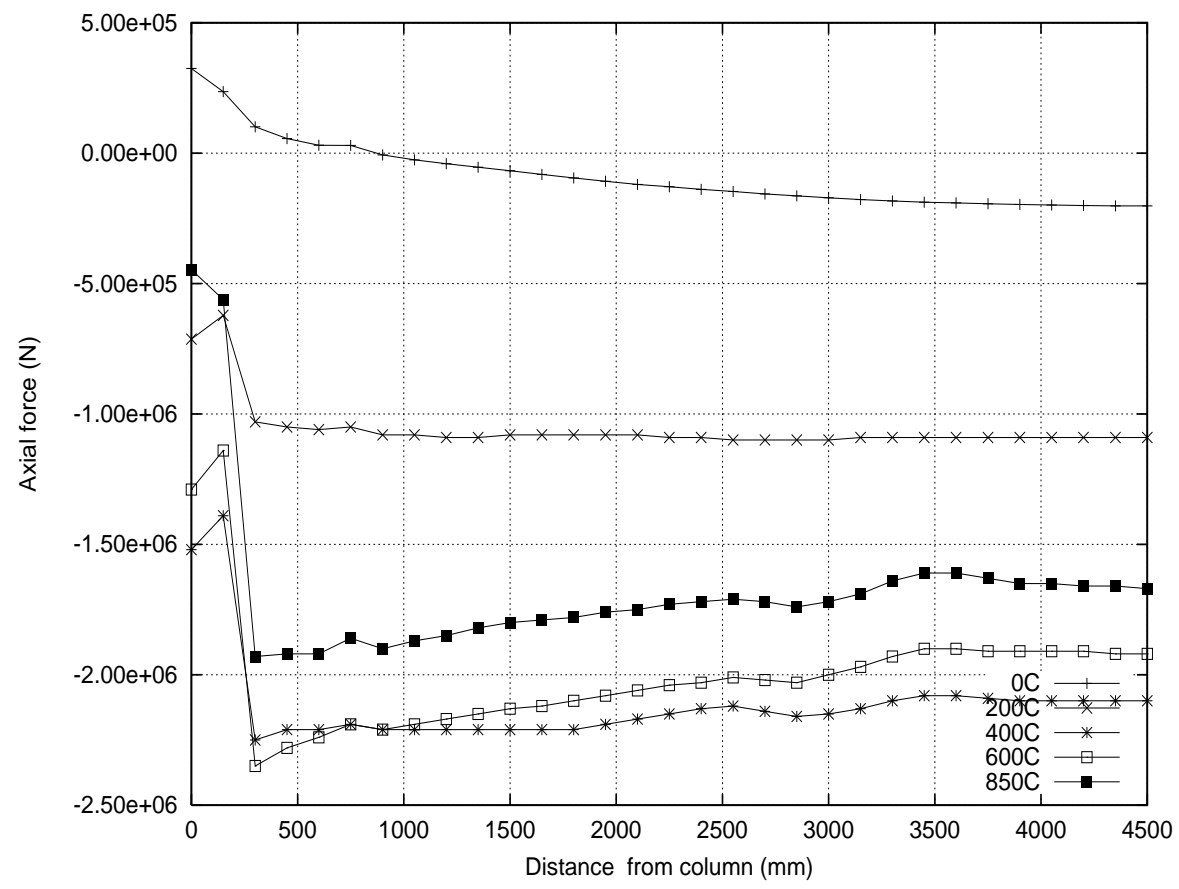

Figure 14: 


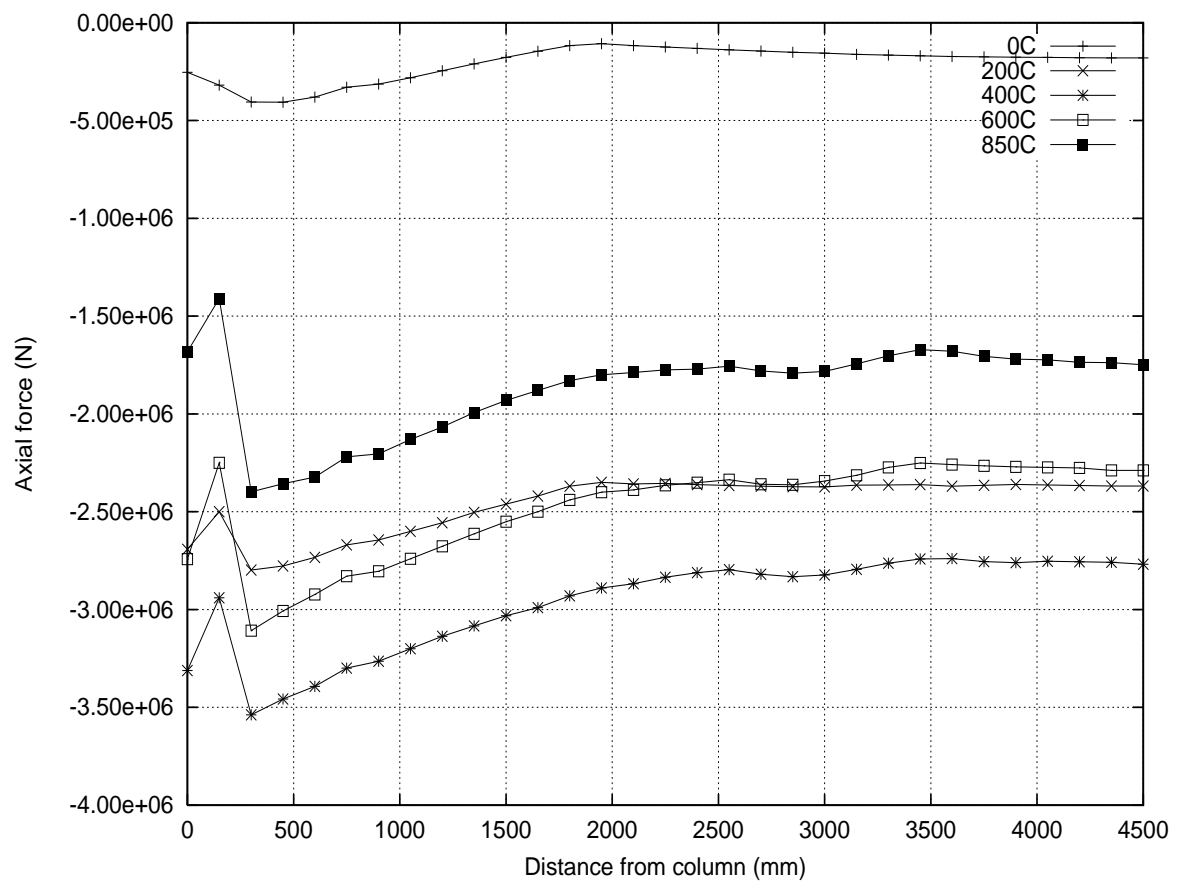

Figure 15: 


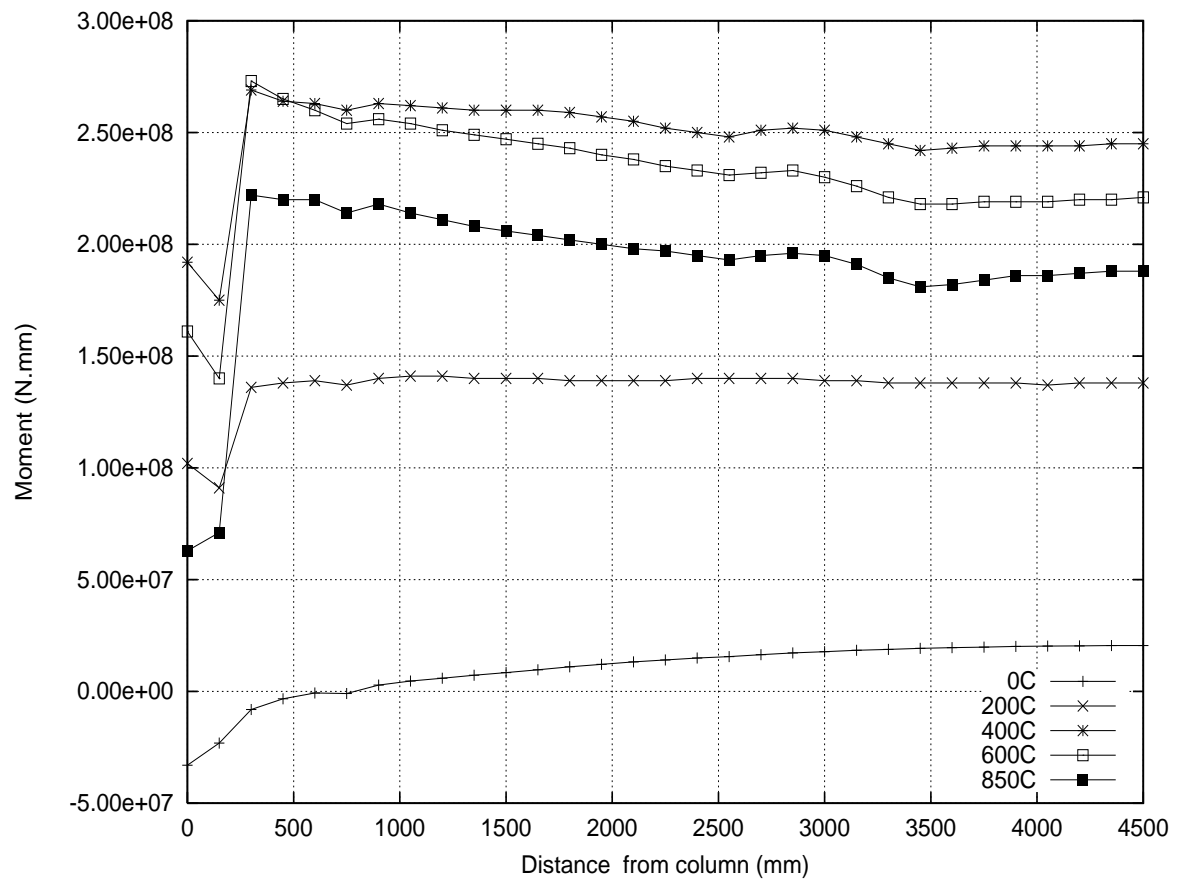

Figure 16: 


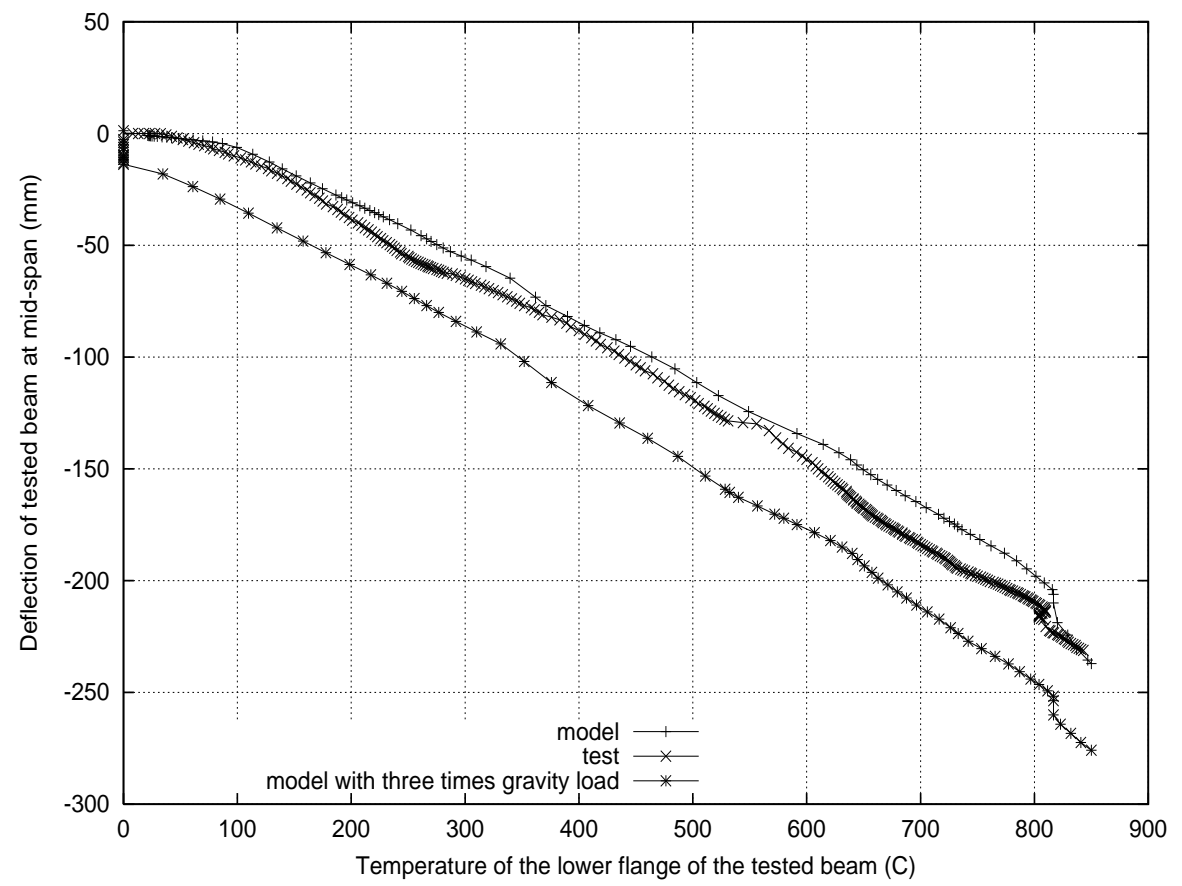

Figure 17: 


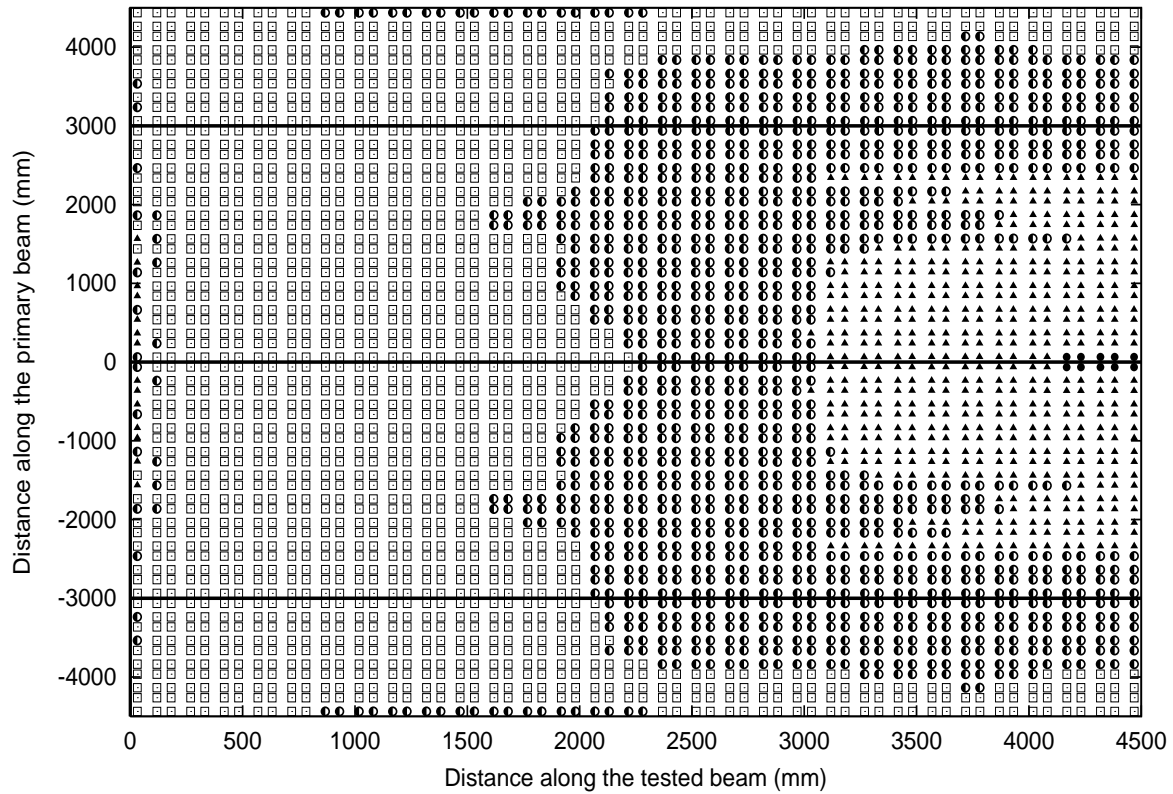

\begin{tabular}{rrr} 
strain $<0$ & $\square$ & $0.001<$ strain $<0.002$ \\
$0.0000<$ strain $<0.001$ & o & strain $>0.002 \quad$. \\
\hline
\end{tabular}

Figure 18: 